\title{
Two cases of Mycobacterium haemophilum infection in a renal-dialysis unit
}

\author{
ANNE GOUBY, B. BRANGER*, R. OULES* and M. RAMUZ \\ Laboratoire de Bactériologie and *Service de Nephrologie, CHRU de Nimes 5, rue Hoche, Nimes, France
}

Summary. Two cases of Mycobacterium haemophilum infection in renal-transplant patients occurred in the same hospital department. This raised the possibility that infection may have been acquired in hospital.

\section{Introduction}

Mycobacterium haemophilum, first recorded by Sompolinsky et al. in 1978, is a known pathogen of renal-transplant recipients. Many cases of infection of such patients have been recorded in Australia and the USA (Mezo et al., 1979; Davies et al., 1982; Lichtenstein and MacGregor, 1983). In France, the first case reported was in a patient admitted to this hospital in 1982 (Branger et al., 1985). The occurrence of a second case in the same department led us to investigate the possibility of person-toperson transmission of this mycobacterium in hospital.

\section{Patients and laboratory methods}

\section{Cases histories}

Patient no. 1, who was born in Mauritius, underwent renal transplantation in March 1982 at the age of 48 years. He was given immunosuppressive treatment with prednisolone, azathioprine and anti-lymphocyte serum. Four months after the operation, he developed a painful swelling of the left middle finger with a purulent discharge, then nodular lesions on the left ankle and the face. He was admitted to hospital in November 1982 and he was discharged in April 1983. Acid-fast bacilli, identified afterwards as $M$. haemophilum, were isolated from the pus. The lesions were treated surgically and by the administration of minocycline, and the patient's condition improved. A clinical recurrence without bacteriological confirmation occurred in 1983; the lesions healed after the administration of erythromycin $(2 \mathrm{~g} /$ day $)$ for 2 months (Branger et al., 1985).

Patient no. 2, aged 48 years, received a first renal transplant in April 1981; this was rejected. He remained in hospital from April 1981 to June 1982. He was given prednisolone $1 \mathrm{~g}$ /day intravenously in March 1982 for 3 days. A second transplant was made in August 1983. He

Received 21 July 1986; revised version accepted 5 Mar. 1987. was given immunosuppressive treatment (anti-lymphocyte serum, azathioprine and prednisolone $15 \mathrm{mg} /$ day). After a month, there were signs of rejection and the patient was given increased corticosteroid therapy. He was re-admitted to the nephrology department in April 1984 suffering from pain in the left knee, and $M$. haemophilum was isolated from the pus obtained by aspiration. The initial treatment with isoniazid and ethambutol was unsuccessful and was replaced by rifampin plus minocycline. He was discharged on 24 April 1984. A second aspirate in May 1984 still contained acid-fast bacilli. Treatment with minocycline alone was continued until October 1984; the lesions healed.

\section{Culture media}

The following media were used: Loewenstein-Jensen (LJ) medium, LJ with the addition of ferric ammonium citrate $2 \% \mathrm{w} / \mathrm{v}$; chocolate agar (Columbia Agar base with heated sheep blood $5 \% \mathrm{v} / \mathrm{v}$ ); Columbia agar base plus unheated sheep blood $5 \% \mathrm{v} / \mathrm{v}$; and Sabouraud's agar.

\section{Biochemical tests}

Cultures on $\mathrm{LJ}$ medium plus ferric ammonium citrate were used to study biochemical features by standard methods (Sompolinsky et al., 1978).

\section{Susceptibility testing}

MICs of antimicrobial agents were determined on chocolate agar in which serial dilutions of the agent had been incorporated. A drop $(5 \mu \mathrm{l})$ of a suspension containing $c .10^{7}$ viable units of organisms per $\mathrm{ml}$ was placed on the surface of the medium; incubation was at $28^{\circ} \mathrm{C}$ for 7 days.

\section{Bacteriological testing of water}

Samples of water $(100 \mathrm{ml})$ were examined for $M$. haemophilum by filtration and culture on chocolate agar at $28^{\circ} \mathrm{C}$. 


\section{Results}

In unhomogenised samples of pus, strongly acid fast organisms occurred singly or in cordlike formations. Primary cultures on $\mathrm{LJ}$ medium at $37^{\circ} \mathrm{C}$ and on Sabouraud's agar at $28^{\circ} \mathrm{C}$ showed no evidence of growth after incubation for 2 months. Cultures on chocolate agar incubated at $28^{\circ} \mathrm{C}$ yielded colonies after 10 days. These were wax-like, non-pigmented and non-chromogenic. On fresh blood-agar media, such as Columbia sheep-blood agar, the bacteria grew more thinly. Growth also occurred on LJ medium supplemented with ferric ammonium citrate. On all these media the optimum temperature was $28-30^{\circ}$. Growth was improved by the addition of $\mathrm{CO}_{2} 10 \%$.

The organisms gave negative results in tests for catalase activity at $70^{\circ} \mathrm{C}$ and for peroxidase activity; Tween 80 was not hydrolysed and nitrates were not reduced. Minimum inhibitory concentrations ( $\mathrm{mg} /$ 1) were as follows: rifampicin 0.2 ; erythromycin 0.6 ; minocycline 2.5 ; doxycycline 2.5 ; trimethoprim 6 plus sulphamethoxazole 30 ; isoniazid $>10$; amikacin $>100$; kanamycin $>100$.

In all, 20 samples of water were collected in the nephrology department and the dialysis unit between April 1984 and May 1984. Cultures of them failed to yield $M$. haemophilum.

\section{Discussion}

The scarcity of $M$. haemophilum in Europe and the appearance of two cases in the same department led us to consider potential sources of contamination. There are at least two possibilities - that the two patients were infected concomitantly from a single source, or that the infection was transmitted from patient no. 1 to patient no. 2. The infection of

\section{REFERENCES}

Abbott M R, Smith D D 1980 The pathogenic effects of Mycobacterium haemophilum in immunosuppressed albino mice. Journal of Medical Microbiology 13:535-540.

Bolan G et al. 1985 Infections with Mycobacterium chelonei in patients receiving dialysis and using processed hemodialyzers. Journal of Infectious Diseases 152:1013-1019.

Branger B. et al. 1985 Mycobacterium haemophilum and Mycobacterium xenopi associated infection in a renal transplant patient. Clinical Nephrology 23:46-49.

Davis B R, Brumbach J, Saunders W J, Wolinski E 1982 Skin patient no. 2 developed long after that of patient no. 1 , but we do not know how long the organism can survive in a carrier or the length of the incubation period. In mice, at least, the pathogenicity of $M$. haemophilum is strongly enhanced by treatment with corticosteroids (Abbott and Smith, 1980). The patients may have had asymptomatic infections for some time, symptoms appearing only after they were given intensive corticosteroid treatment.

We investigated the possibility of a common source for the infections. Water-borne outbreaks of mycobacterial infection in transplant units have been reported (Bolan et al., 1985). The water supplies in the nephrology and haemodialysis departments were analysed. We failed to detect $M$. haemophilum in water from multiple sites. However, these investigations were undertaken only after the identification of the organism in the second patient, and therefore long after the date of putative contamination.

Transmission from patient to patient is a possibility; both knew each other very well whilst in hospital and at one time occupied neighbouring beds and they used the same bathroom during 10 days from 1 April 1982 to 9 April 1982. At that time, patient no. 1 had just received a renal graft and patient no. 2 was being dialysed.

Patient no. 1 is a native of the southern hemisphere, but he had never been in Australia, where most of the reported cases of $M$. haemophilum infection have been found; he had lived in France since 1977. Patient no. 2 had never left the Nimes area. No mycobacteria were found in the water from his house supply. No new cases of this infection have been observed in the hospital since 1984.

lesions caused by Mycobacterium haemophilum. Annals of Internal medicine 97:723-724.

Lichtenstein I H, MacGregor R R 1983 Mycobacterial infections in renal transplant recipients: report of five cases and review of the literature. Reviews of Infectious Diseases $\mathbf{5}$ : 216-226.

Mezo A, Jennis F, McCarthy S W, Dawson D J 1979 Unusual mycobacteria in five cases of opportunistic infections. Pathology 11 : 377-384.

Sompolinsky D, Lagziel A, Naveh D, Yankilevitz T 1978 Mycobacterium haemophilum sp. nov., a new pathogen of humans. International Journal of Systematic Bacteriology 28: $67-75$. 


\section{OBITUARY NOTICE}

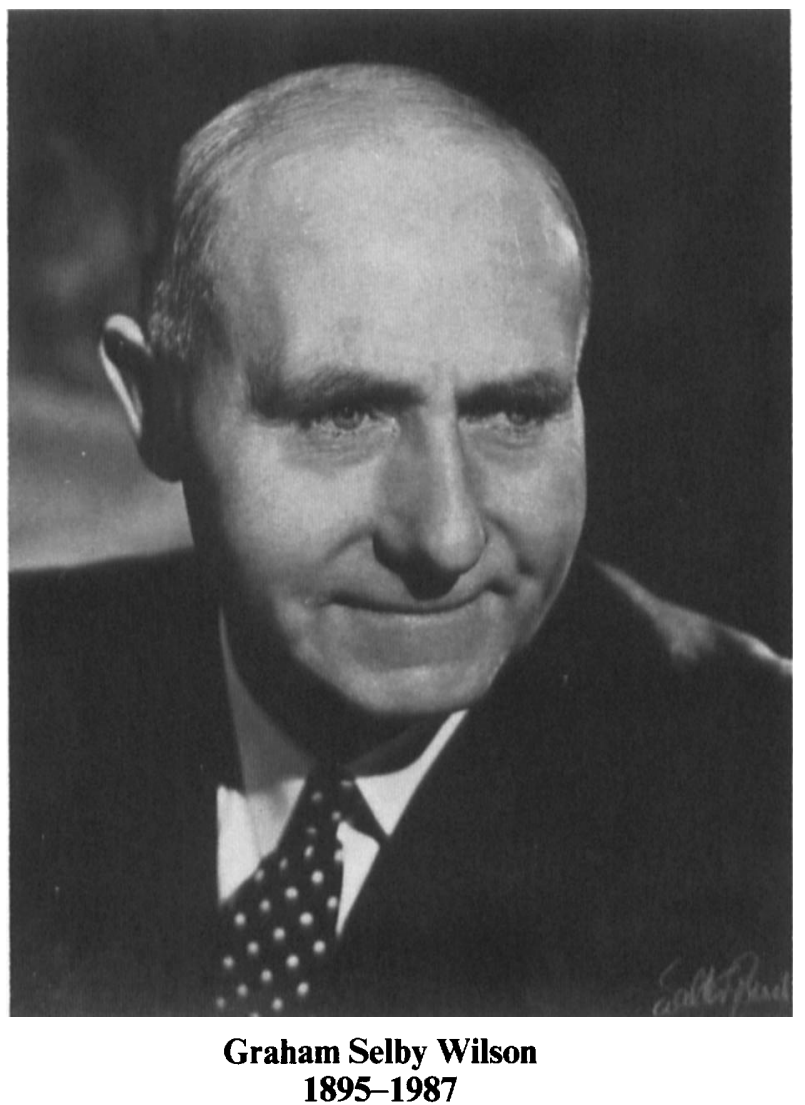

Sir Graham Wilson was probably the most influential British microbiologist of the 20th century. His career extended over more than 70 years, from his first scientific paper, published in 1917 and reporting work done as a medical student at Charing Cross Hospital Medical School, to a study of early bacteriologists completed a few weeks before his death. In addition to many individual contributions to bacteriology and the epidemiology of communicable diseases, he was a pioneer in the postgraduate education of medical microbiologists, an outstanding exemplar of good scientific writing, and the main architect of the Public Health Laboratory Service (PHLS).

After a shortened war-time training in medicine, Wilson joined the Royal Army Medical (RAM) Corps, serving first in the Enteric Laboratory at Kasauli, India (1916-18) and then briefly at the RAM College, London. In 1920 he returned to Charing Cross to join Dr W. W. C. Topley in his studies of the genesis of epidemics among caged mice.
In 1923 the two workers moved together to Manchester University where they found themselves in a laboratory that was responsible - as were several others in the great towns of northern England-for providing bacteriological services for municipal public-health departments. They soon recognised the need for well trained senior staff in such laboratories, and within a year had started the first British full-time postgraduate course in bacteriology, leading to a Diploma in Bacteriology (Dip. Bact.). This experience revealed to them the absence of a suitable advanced textbook for the students, and soon they were preparing the first edition of Topley and Wilson's "Principles of Bacteriology and Immunity".

This work set a new standard for textbooks of medically orientated microbiology. Indeed it did much to define this discipline by establishing for it a suitable "mix" of basic knowledge of the biology of micro-organisms and the pathology of bacterial diseases with their practical applications to medicine. One of its chief strengths was the authors' 
clear recognition of which matters could be disposed of by bald statements of fact and which merited balanced discussion with key references. Another was the great clarity and elegance of the English in which it was written.

The Manchester experience also transformed Wilson from an academic to a public-health bacteriologist. Henceforth he would devote himself to "problem-solving" activities concerned with the prevention of communicable diseases. The University laboratory had for many years been a centre for the study of tubercle bacilli in urban milk supplies, and Wilson became deeply concerned with the prevention of milk-borne disease.

In 1927 Topley and Wilson moved back to London as Professors of Bacteriology at the London School of Hygiene and Tropical Medicine and immediately established a second Dip. Bact. course. Their close intellectual collaboration continued, and in 1936 they produced a 2 nd edition of "Topley and Wilson", but their interests were now diverging. Topley continued to study experimental epidemics while Wilson was mounting a multi-directional attack on the problems of milk-borne disease. Not only did he investigate the presence of tubercle bacilli and Brucella abortus in milk, he made comprehensive studies of the properties of the organisms themselves. By this time he was a proponent of pasteurisation and was establishing the precise conditions of time and temperature for the destruction by heat of pathogens in milk; he and his collaborators even investigated the effect of pasteurisation on its nutritive properties. An outstanding achievement of this period was a masterly analysis of the sources of error in the detection of tubercle bacilli by microscopy, culture and animal inoculation.

During the 1930s Topley and Wilson had been developing their ideas about the role of the laboratory in the control of communicable diseases, and by 1938 were teaching their students that this could be done effectively only if a comprehensive, free, country-wide network of public-health laboratories was created. These laboratories should take a more active part in the field investigation of epidemics than did the existing laboratories and should initiate studies of the mode of spread of infection and of the efficacy of preventive measures.

The fact that such a service, albeit limited in scope and extent, was to come into existence at the outbreak of World War II can be attributed in large measure to the influence of Topley, who was Chairman of the Medical Research Council (MRC) Subcommittee charged by the Government with planning a "civilian bacteriological service to act in time of war". This so-called Emergency PHLS was to be under the direction of the MRC; its services were to be, with certain exceptions, free to users, but its activities were to be limited to parts of the country deemed to be poorly provided with laboratory facilities: mainly to rural parts of southern England and of Wales. Existing university and municipal public-health laboratories in the North, and the laboratories of the London County Council, with their wartime country branches, would remain outside the Service but would have loose links with it. The staff of the new Service would be drawn from various university departments and research institutes and would move into place only when war was declared. At this stage the functions of the Service were specified only in the most general terms.

Topley presided over the mobilisation of the Emergency PHLS in September 1939 but left it in the spring of 1941 to join the Agricultural Research Council. Wilson began the War in the Service's Oxford laboratory, of which he had charge from April 1940, and within a few weeks of Topley's departure was appointed Director of the Service. This was a formal recognition of the fact that, in the previous 18 months, Wilson and the Oxford laboratory had established intellectual leadership of the Service and were setting the pattern of its activities nationally. The great epidemics expected to sweep the country after the mass destruction of towns by aerial bombardment had not materialised, but it was soon realised that there was a potential role for the Service in tackling the hitherto neglected problems of communicable disease in rural and small-town Britain, which were now somewhat intensified by the presence there of thousands of evacuees from the cities and of many military recruit-camps. This provided an opportunity to apply Topley and Wilson's ideas of how a comprehensive laboratory service for the control of communicable diseases should function. Wilson had great success in persuading health authorities in the Oxford region to accept active laboratory collaboration in the investigation of epidemics, notably but not exclusively of diphtheria, and in mobilising them to take part in collaborative trials of preventive measures. The Oxford laboratory had from the outset been designated the Service's centre for epidemiological intelligence. Wilson siezed this opportunity by producing, from November 1939, a Monthly Bulletin that gave accounts of model investigations performed in the Service. His skilled editing ensured that the Bulletin carried a message of good laboratory and epidemiological practice and highlighted the benefits of active laboratory 
participation in field investigations and of planned collaborative studies.

The growing consensus in the Service about its role in wartime Britain was accelerated after Wilson became Director. He began to pay regular annual visits to all the laboratories; these were a combination of searching inspection, seminar, and social occasion, and did much to foster a corporate identity in the Service. He introduced the practice of pre-editing all the scientific papers written by members of the Service, thus establishing its reputation for literacy and clear thought.

Wilson's appointment as Director brought him into contact with Dr (later Sir) Landsborough Thomson, the MRC official responsible for the general administration of the Emergency PHLS. From Thomson, Wilson absorbed the non-bureaucratic "minimalist" concept of administration characteristic of the MRC of those days. This was to set the pattern for the Service long-term: a very small central administrative apparatus; little decision-making by committee; a benevolent dictatorship in which major issues were decided centrally and action was devolved to carefully selected senior staff in the individual laboratories.

For the remainder of the War years, Wilson directed the Oxford laboratory while commuting to London to direct the Service. In Oxford he took an active part in the day-to-day work of the laboratory; among his many practical activities was the development, with J. D. Atkinson, of the phagetyping system for Staphylococcus aureus that is still in use, in modified form, over 40 years later. $\mathrm{He}$ continued to edit the Monthly Bulletin and established the Weekly Summary of all laboratorydiagnosed cases of infection that was to develop later into a national surveillance system for communicable diseases.

The PHLS (with the word "Emergency" deleted from its title) became a permanent feature of the National Health Service in 1946, but it continued to be administered by the MRC on behalf of the Government until 1961. Wilson was its Director until 1963; during the 17 years that he held this post he presided over a considerable expansion in its size, an even greater increase in its work-load, and a remarkable growth in its scientific activities and prestige.

In 1946 the Service was little larger than it had been in 1939, comprising some 20 laboratories, all except three of them small and most of them in the rural south and west of the country. During the next 10 years it can be said to have become a "national" service. The number of laboratories trebled, mainly from the absorption of university and municipal laboratories in large urban centres, a number of them soon to become regional laboratories in the expanded service. Early in this period the Central Public Health Laboratory at Colindale was formed to house the growing number of "reference" laboratories and other centres of special expertise. Many of the laboratories now joining had earlier been loosely associated with the Service and had already absorbed a good deal of its ethos. This process was accelerated by the transfer of senior staff from the "emergency" laboratories to those newly incorporated, but Wilson's personal influence was again a vital factor in transforming them into PHLS-like laboratories. His work-load during the time of rapid expansion became truly prodigious. He continued to make regular annual visits to all the local laboratories, soon to number over 60 , and fortnightly visits to the central laboratory at Colindale; these were always occasions for thorough and unhurried discussion. He read in manuscript nearly all of the scientific papers written by members of the Service and extensively rewrote the worst of these. He was a shrewd and often hard negotiator with universities and health authorities for the take-over of their laboratories. Later he became an experienced planner of new laboratory buildings, making detailed sketch plans for nearly all of the laboratories built by the Service during his time as Director, so that they tended to have a recognisable "Wilson" style.

One of the most important of the instruments designed for maintaining PHLS identity was the so-called "Staff Committee". This regular gathering of heads of laboratories was not, despite its name, a decision-making body. Its functions were to distribute information about administrative arrangements in the Service and to educate and motivate its members. The latter was by far its more important role: to distribute reliable and upto-date technical information and to encourage members to undertake collaborative investigations of unsolved problems. This was linked with the Service's permissive attitude to the choice of technical methods; when significant differences in practice had been identified a collaborative trial was organised and the most effective method was eventually adopted by all.

Another factor making for intellectual homogeneity was the method of selecting recruits. Until around 1960, all senior staff were chosen by Wilson himself, after careful enquiries into their background, a long and detailed personal interview, and a report from a psychologist. Increasingly, appointments were made from the Service's own trainees, who had undergone a carefully structured postgrad- 
uate training which included a period of full-time research and attendance at a Dip. Bact. course. Indeed, the Service had established formal training for its recruits before this began in other branches of laboratory medicine.

During Wilson's period as Director of the PHLS, its scientific prestige was unchallenged and the quality of the service provided was generally accepted to be of the highest order. However, by the late 1950 s its very successes were leading to some administrative difficulties. Nearly all of its constitutive laboratories were now sited in or near general hospitals and they had established their technical ability to provide a microbiological service for the hospital as well as for the local community. In many cases, arrangements had been made for the Service to take on this additional task, often on financial terms that were over-generous to the hospital in question. On the one hand, growing demands for hospital microbiology were tending to eat up the Service's resources, and on the other, hospital microbiologists were coming to fear "takeover" by the PHLS. Fortunately, after a period of uncertainty, a sensible compromise directed the Service along a middle course.

All through Wilson's time as Director of the PHLS he devoted a considerable part of his time to updating "Topley and Wilson". After the death of Topley in 1944, he was responsible for the preparation of five more editions of the work in collaboration with A. A. (later Sir Ashley) Miles, and latterly with the help of junior colleagues. Up to the 7th edition (1983-84) he continued to write large sections of the book himself and was the main arbiter of its style and scientific stance.

Wilson's intellectual dominance of the PHLS can be attributed to his phenomenal knowledge of microbiology and his outstanding ability to formulate clear, logical solutions to the problems of communicable disease. These characters became apparent to all because he was a superb communicator, both orally and in print. However, he did not merely convince; he motivated his colleagues to do his will and inspired their personal loyalty. This he did by his seriousness, integrity and high moral purpose.

Sir Graham Wilson: MB, BS 1916; MD 1919; DPH 1920; MRCP 1920; FRCP 1930; Knighthood 1962; Hon. LLD Glasgow 1962; Hon. FRCPath. 1973; FRS 1978; Hon. Member of the Pathological Society of Great Britain and Ireland. 